\title{
HÁbitos CUlTurales y POSTPROdUCCIÓN EN JÓVENES ESTUDIANTES DE LA UVI-HUASTECA
}

\author{
Claudia Morales Silva
}

Resumen: En este escrito se identifican, a partir de un trabajo etnográfico realizadoen 2007 y 2008, algunos hábitos culturales de jóvenes estudiantes de la Universidad Veracruzana Intercultural (UVI), en su sede-regional Huasteca. A partir de estos hábitos culturales se pretende iniciar una caracterización de procesos de postproducciones de estos universitarios y de las formas en que los estudiantes de la primera y segunda generación, en su trayecto por la misma, incorporaban y reapropiaban distintos objetos y relatos, para (post)producir sus propias interpretaciones y significaciones. El referente postproducción servirá de herramienta para observar parte del proceso de reconversión e incorporación de patrimonios culturales, resultado parcial de la inserción a la vida escolar universitaria con enfoque intercultural.

Palabras clave: jóvenes universitarios, postproducción, procesos de hibridación, hábitos culturales.

Enviado a dictamen: 08 de nero de 2012

Aprobación: 11 de abril de 2012

Revisiones: 1

Mtra. Claudia Morales Silva, Tesista del programa de Doctorado en Antropología y Bienestar Social, por la Universidad de Granada, España. Docente de la Universidad Pedagógica Veracruzana. Temas de especialización: culturas juveniles, estudios interculturales y educación intercultural. Correo electrónico: upvdialogo@gmail.com.
Abstract: This paper identifies, using ethnographic information collected between 2007 and 2008, some cultural habits of the young students of Universidad Veracruzana Intercultural (UVI), regional headquarters, Huasteca. From these cultural habits, I begin a characterization about the postproduction process of these university students, the manners in that the first and second generation, in their way through the University, incorporate and re-appropriate objects and stories, and post-produce them under their own interpretation and meanings. The concept of post-production is useful as a tool for observe part of the reconversion and incorporation process of cultural patrimonies, as a result-in part- of the insertion in the intercultural university life.

Keywords: Students, post-production, hybridization processes, cultural habits.

E importante para este trabajo, ${ }^{1}$ describir algunos de los hábitos culturales de los estudiantes de la Universidad Veracruzana Intercultural (UVI), en su sede-regional Huasteca y analizarlos a partir del concepto de postproducción (Bourriaud, 2004). El concepto de postproducción es útil para reflexionar sobre los procesos de re-apropiación de distintos objetos y relatos por jóvenes estudiantes de educación superior en el contexto de una universidad 
con un discurso intercultural, puesto que permite observar el modo en que convergen la institución de educación formal y las Tecnologías de la Información y la Comunicación (TIC), en la generación o incorporación de hábitos culturales paralelos a los distribuidos por las industrias culturales.

La argumentación de este análisis seguirá la siguiente estructura, primero comenzaré definiendo los dos conceptos centrales que serán el eje de este trabajo: postproducción y procesos de hibridación, para dar paso en segundo término, a una breve descripción del contexto social y cultural, del lugar donde se ubica la universidad y de las comunidades a las que pertenecen los estudiantes. Como tercer punto, se sintetizará el discurso de la institución (UVI) y se expondrán algunas de sus prácticas escolares. En cuarto lugar, se describirá la metodología a partir de la que se obtuvo la información con el fin de caracterizar a los estudiantes y algunas formas en que, desde lo local, se redimensiona lo planeado por la institución ya sea reconfigurando, adaptando, rechazando, usando, incorporando o reciclando algunos de los objetos y los relatos que estuvieron a su alcance en ese espacio universitario emergente y con acceso a las TIC. Por último, a partir de los elementos expuestos, se presenta una reflexión desde el concepto de postproducción que nos permite comprender el proceso por el cual los estudiantes, desde sus contextos rurales e indígenas, se apropian y generan diversos contenidos, producto de su acceso a dispositivos tecnológicos contemporáneos y al consumo de las industrias culturales globales.

\section{I.}

Para estudiar actualmente los procesos de construcción identitaria de los jóvenes, se requiere entender a los colectivos juveniles como habitantes de un mundo interconectado a escala planetaria, donde la sola referencia a sus familias o contextos inmediatos no basta para comprender los repertorios culturales a los que tienen acceso, aunque estos sean precarios, desiguales y diversos. Ahora bien, partiendo de la globalidad de estos procesos de intercambio y negociación cultural e identitaria y para acercarnos a las cotidianeidades de los actores rurales que se encuentran insertos en la vida escolar de nivel superior, se requiere contar con elementos conceptuales y metodológicos que nos permitan identificar los entramados socio-culturales que han posibilitado actualmente la existencia del ser joven universitario rural y/o indígena. Para ello, a continuación, a partir de las categorías procesos de hibridación y de postproducción, se buscará describir y comprender los hábitos culturales de los estudiantes de primera y segunda generación de la Universidad Veracruzana Intercultural, en su sede regional Huasteca.

Para empezar es necesario definir el concepto postproducción. Para ello recurro a Nicolas Bourriaud y a su libro titulado Postproducción (2004), según el cual, el concepto de postproducción: "Designa el conjunto de procesos efectuados sobre un material grabado: el montaje, la inclusión de otras fuentes visuales o sonoras, el subtitulado, las voces en off (...)" (2004: 7). Además Bourriaud señala que desde los años noventa existen artistas de la postproducción que parten de materiales originales para otorgarles una nueva forma y un toque distintivo. Se trata de artistas que reciclan, que buscan usar y encajar en nuevas cadenas de significado lo ya producido. A parte, alude en sus ejemplos de "postproductores" a creadores del reciclaje, a los artistas que llama de la postproducción y a figuras del DJ y del web surfer (internauta), que trascienden la propiedad privada "pirateando" las formas originales y reapropiándose de ellas para generar nuevos usos.

El concepto de postproducción de Bourriaud, se puede poner en relación con los procesos de hibridación, ya que “...a menudo la hibridación surge de la creatividad individual y colectiva. No sólo en las artes, sino en la vida cotidiana y en el desarrollo tecnológico. Se busca reconvertir un patrimonio (...) para insertarlo en nuevas condiciones de producción 
y mercado" (García-Canclini, 1989). Si con Bourriaud queda claro que la postproducción es reapropiación de materiales ya creados para reciclarlos, con García Canclini, enriquecemos la idea de reapropiación con la de reconversión de patrimonios culturales por parte de todos los sectores sociales, pues la hibridez y los procesos que genera, como la reapropiación, interesan no sólo a los sectores hegemónicos, sino también a los sectores populares que esperan apropiarse de los beneficios de la modernidad.

Así, podemos decir que obtener los beneficios de la modernidad implica, siguiendo a García Canclini, situar a los actores en procesos de hibridación que los llevan a reapropiarse de lo ya producido y reconvertirlo, pero entonces, idónde queda la creatividad del proceso de reapropiación para identificar a ésta como una postproducción? Retomando una vez más a García Canclini podemos decir que en la actualidad: "La creatividad aparece menos como una virtud profesional (de artistas, escritores y científicos) o una gracia de aristócratas; se anuncia como una virtud para la generación de valor en el trabajo y en el disfrute personal" (2007: 54). Parece entonces claro que no sólo los artistas postproducen sino que, en realidad, todos nos reapropiamos y reconvertimos. Sin embargo, esto no implica que se pueda generalizar el tipo y forma de reapropiación y reconversión pues no todos nos reapropiamos de todo en igualdad de circunstancias y para los mismos fines de reconversión.

Los adelantos tecnológicos permiten, a través de las actuales industrias culturales, procesos de reapropiación y reconversión distintos (planetarios), desarrollados por receptores activos en diversos patrimonios culturales. Estos receptores son activos porque, desde ámbitos configurados por una matriz cultural peculiar constituida por una diversidad propia y con una desigualdad socioeconómica estructurante, generan sus propios procesos de hibridación y postproducción. El concepto de matriz cultural no implica que un grupo de sujetos actúen como una unidad cerrada, homogénea y estática, más bien, implica una diversidad intra-cultural, inter-actoral, organizada interiormente por procesos socio-culturales, que dan distintas posibilidades de sentido a sus miembros. Estas posibilidades de sentido se ven reflejadas de manera individual y colectiva en las acciones y pensamientos de acuerdo a la posición ocupada en el espacio social por cada sujeto y/o grupo. La significación de los procesos culturales por parte de los sujetos es producto de variadas circunstancias, entre otras: la época, el medio ambiente, la región, la clase social, la edad, el género, la instrucción escolar, la cosmovisión, etcétera. Así, las TIC, como se llama a las tecnologías de información y comunicación, están hoy día al alcance de la diversidad cultural global para su disponibilidad y uso de manera diferente y desigual.

Las TIC posibilitan a un gran número de personas el acceso a otros patrimonios culturales, incluidos los difundidos por las industrias culturales, que pueden ser reapropiados y reconvertidos según la disposición y la posición de los sujetos. Generando estas posibilidades de acceso a diversos reportorios culturales o nuevos hábitos culturales en quienes, por ejemplo, acceden a Internet, se observa el interés por descargar de manera gratuita libros, revistas, música, imágenes, películas, etcétera, bien para compartir con otros internautas estos productos, sean de autores desconocidos o "consagrados", o bien, para generar creaciones de autoría propia (escritos, música, imágenes). Al subir algo a la red y ponerlo a disposición de otros, cualquier internauta, con la adecuada tecnología, puede descargarlo en su computadora, celular, etcétera. ${ }^{2}$

Dado lo anterior parece necesario realizar investigación empírica sobre las formas en que sujetos pertenecientes a colectivos con escasas oportunidades de acceso a dispositivos tecnológicos como los señalados, se incorporan al uso de las TIC. Particularmente, es de mi interés el caso de los jóvenes estudiantes, pues éstos, en los contextos observados, eran los que tenían una mayor posibilidad de acceso y uso de los mismos, 
derivado, en parte, de su inserción escolar. Cabe señalar que, entre los sujetos que podemos generalizar como jóvenes estudiantes rurales e indígenas, tenemos que distinguir a los que han transitado por la escolarización denominada intercultural, pues parte de sus hábitos culturales son producto de procesos de hibridación y de postproducción a partir de intenciones institucionales específicas, derivadas del respeto y valoración de las culturas étnicas locales.

\section{II.}

Como mencioné antes, no se debe concebir a los jóvenes y sus hábitos culturales como producto de intercambios y diálogos entre "pares" a través de las tecnologías de la información. Por el contrario, es necesario reconocer las características de, al menos, parte del contexto. Para esta investigación es en lo local donde interesa describir los rastros que deja la transculturalidad experimentada a partir de estos nuevos hábitos culturales que llevan a la reapropiación y reconversión de lo difundido por las nuevas tecnologías en una universidad. Hasta aquí se puede considerar como habitual y deseable que jóvenes de veintitantos años se apropien de las nuevas tecnologías de la información con el apoyo de la educación superior, pero entre las particularidades de esta universidad, que la convierten en un ámbito de interés para realizar esta investigación, se halla la ubicación de la misma. La Universidad Veracruzana Intercultural (UVI), sede regional Huasteca, inició cursos en el año 2005 y, desde entonces, se encuentra ubicada en lo que se ha denominado como Huasteca baja veracruzana, concretamente en la cabecera municipal de Ixhuatlán de Madero, municipio donde, apenas en los años ochenta, hubo teléfono público y, en el que el primer local con renta de internet empezó a funcionar a finales del año 2004. La existencia de señal para celulares empezó a funcionar en febrero de 2012, aunque ya se usasen antes, como se podrá apreciar más adelante. Además, Ixhuatlán tuvo su primera carretera hace aproximadamente quince años. Antes los caminos eran de terracería y brechas en muchas localidades de ese municipio y en los municipios vecinos. Así, la construcción de la carretera federal Álamo-Chicontepec conectó al municipio y en general a la región con otras zonas del estado y del país. La construcción de la carretera a mediados de los noventa provocó, entre otras situaciones, el desplazamiento del poder económico, político y comercial de la cabecera municipal Ixhuatlán de Madero a otras poblaciones del mismo municipio como Colatlán o Llano de en Medio. Las poblaciones señaladas por las que atravesó primero la carretera pronto se convirtieron desde 1997 en rivales de Ixhuatlán por las ventajas de acceso a la carretera federal.. Sin embargo, esta desventaja para la cabecera municipal y comunidades aledañas a Ixuatlán, se ve aminorada en noviembre de 2007, cuando se inaugura el puente río Vinazco que permite las comunicaciones incluso en época de lluvias. Cabe señalar que hasta antes del 2007, al desbordarse el río Vinazco, las comunidades del lado en que se encuentra la cabecera municipal quedaban incomunicadas.

Ixhuatlán es también un municipio con presencia de población monolingüe y/o bilingüe en distinto grado. Cuenta con hablantes de cuatro lenguas de etnias autóctonas de México (nahuas, totonacas, tepehuas, otomíes),cada una con variantes dialectales diversas en la región. Además, las etnias que se localizan en el municipio y en los municipios vecinos, continúan realizando prácticas de sincretismo religioso y cultural características del área como las limpias o el xantollo. Asimismo, muchas localidades de la Huasteca baja aún conservan formas de organización social comunitaria. ${ }^{3} \mathrm{Al}$ ser un municipio poco comunicado y con una población que hasta hace poco tiempo estuvo desconectada ${ }^{4}$ de la vida más allá de sus comunidades, se denominó a su cabecera municipal Ixhuatlán del Matadero, por los frecuentes asesinatos entre individuos de la región, fuera para robarles, ajustar cuentas, por "borrachera", etcétera. También es conocido como 
"del Matadero", por la presencia de cuerpos policíacos o militares para reprender revueltas de "indios y campesinos" inconformes por la falta de servicios o la redistribución de los mismos.

Es en este espacio que los ganaderos y el gobierno — estatal y federal - llaman la Huasteca, donde se hablan mayoritariamente lenguas indígenas y hay dificultades de acceso a la educación superior, es el lugar en el que, comenzando el siglo XXI, empieza a funcionar la UVI. Su creación surge a partir de movilizaciones para "tener una universidad india", movilizaciones a las que se sumaron el Seminario de Educación Multicultural de Veracruz de la Universidad Veracruzana (UV) y diversos profesionistas indígenas y no indígenas. El año 2005 se logra un acuerdo entre la UV y la Secretaría de Educación Pública a través de la Coordinadora General de Educación Intercultural Bilingüe, que implicó la creación del programa ${ }^{5}$ Universidad Veracruzana Intercultural.

III.

El trabajo de este programa universitario comenzó ese mismo año. Grosso modo, se puede caracterizar a la UVI como una institución que busca impartir educación de nivel superior con pertinencia cultural. En cuanto a la forma de trabajo de la UVI-Huasteca, en el 2006, su jornada escolar empezaba a las ocho de la mañana y variaba la hora de salida de los estudiantes, pudiéndose extender hasta las cuatro de la tarde. En el transcurso de esas horas y en otras dedicadas a su formación académica, los estudiantes eran interpelados por los distintos discursos que buscaba transmitir la universidad. Por ejemplo: 1) La convivencia intercultural, algo que "no tienen claro ni maestros ni alumnos", pero que tiene que ver con "ser intercultural", "la buena onda", "ser tolerante", "ser cada uno distinto". ${ }^{2}$ 2) La revitalización de las lenguas indígenas de las comunidades o las de los vecinos en el caso de los monolingües en español. 3) La investigación en grupo, que implica búsqueda de información en equipo, redacción de proyectos, salidas a "campo", es decir a las comunidades, redacción de diarios de campo, grabación de entrevistas, toma de fotografías y videos, tutorías con el asesor de la investigación, consultas de información en Internet, etcétera. 4). La participación en la realización de diversos eventos académicoculturales como el evento de "La lengua materna", "El aniversario del primer año de fundación" y diversas fiestas e intervenciones comunitarias. ${ }^{7}$

Esas y otras experiencias son transmitidas por la institución a los estudiantes desde el discurso oficial y su adaptación local, que varía de acuerdo al docente, grupo, momento, etcétera. Como se puede observar, desde la institución se da importancia a conocer y valorar los patrimonios culturales propios o locales. Por ejemplo, el de los abuelos o los padres, pues muchas veces los estudiantes, como generación joven, se encuentran más interesados en los patrimonios culturales externos difundidos por las industrias culturales, entre otros, los que se transmiten vía televisión, radio e internet, así como la música y las películas piratas (en CD y DVD) a las que tienen acceso. Así, las industrias culturales y sus modelos de consumo, que se refieren a hábitos culturales de otros grupos nacionales, etnias o clases sociales, son muchas veces preferidos por los niños y jóvenes. Esto es constatable, por ejemplo, en la estética de la vestimenta que prefieren, al igual que en el idioma que emplean para comunicarse entre ellos, las imágenes y la música que consumen.

IV.

Antes de describir algunos de los hábitos culturales de los sujetos observados, es necesario presentar mínimamente la manera en que obtuve la información. Del total de 101 estudiantes de la UVI-Huasteca ${ }^{8}$ entrevisté en profundidad a 35, entre los cuales trabajé con trece. Con éstos realicé un acompañamiento más detallado de sus experiencias durante su estancia en 
la Universidad y en Ixhuatlán. Cuando sus padres no habitaban en esta cabecera municipal, visité sus comunidades de origen y entrevisté a sus padres. A partir de los relatos y las observaciones a cerca de las prácticas de los sujetos, busqué caracterizar los hábitos que los distinguen y asemejan a otros grupos de edad, como es el caso de los padres cuando tuvieron la edad de sus hijos, o sus hermanos, que estudiaban otros grados escolares, o ya habían desertado de la vida escolar. Estas entrevistas las realicé intentando evitar respuestas anticipadas a cerca de quiénes eran y qué hacían estos estudiantes al igual que, identificando las formas en que generaban sus postproducciones y sus procesos de hibridación. Cabe reconocer aquí que, pese a mi intención de "objetividad", no de neutralidad, mi comprensión del mundo de vida de estos actores, está sesgada por mis propios horizontes culturales $\mathrm{y}$, por lo mismo, es posible que mi análisis de sus postproducciones no haga justicia a la capacidad de agencia y resistencia que tengan estos jóvenes estudiantes universitarios.

La gran mayoría de los estudiantes entrevistados provenían del municipio de Ixhuatlán de Madero, incluso tres eran oriundos de la cabecera municipal y algunos se habían traslado a vivir al poblado en que se asienta la UVI, por lo que con ellos hubo mayor acceso a observaciones cotidianas. Los estudiantes se tuvieron que trasladar a vivir a Ixhuatlán, entre otros motivos, por la distancia de más de una hora entre sus comunidades y la cabecera municipal, por el poco transporte que hay en la región y para evitar el desgaste de invertir tiempo y dinero en viajar a diario de casa de sus padres o tutores a la escuela o viceversa.

Asimismo, se buscó que la muestra de trece casos fuera representativa de la diversidad de estudiantes: los hay de cinco de las etnias de la región, con distinto grado de bilingüismo, con variadas experiencias de migración, de ambos géneros, de distintos municipios próximos al de Ixhuatlán, con edades comprendidas entre los 19 y 26 años, con capitales culturales diversos y con poderes adquisitivos diferentes. ${ }^{9}$ La gran mayoría de los entrevistados, constituyen la primera generación de su unidad doméstica que tienen estudios más allá de la primaria pues, en general, sus padres estudiaron sólo hasta tercer año de primaria. En cuanto a la diversidad de padres entrevistados, se puede caracterizar sintetizando los motivos que manifestaron para que sus hijos estudiaran el nivel de educación superior. Por ejemplo, ante la pregunta ipor qué darle ${ }^{10}$ educación a sus hijos?, las respuestas más representativas fueron la falta de tierras, ampliar las oportunidades y progresar.

\section{V.}

Los estudiantes de la UVI están inmersos en un proceso de transmisión-adquisición de cultura (cfr. García Castaño,1994), normado y regulado por una institución avalada por el estado, denominada intercultural. Los estudiantes se encuentran transitando por un espacio en el que se busca proporcionarles aprendizajes formales, lo que de manera paralela les posibilite el acceso e intercambio de aprendizajes informales. La transmisión-adquisición de cultura formal e informal, experimentada a partir de la creación de la UVIHuasteca, ha permitido que personas en un rango entre los 19 y 26 años de edad, de orígenes rurales e indígenas diversos, adquieran capitales culturales distintos a los de sus padres, hermanos u otros miembros de sus comunidades. Entonces, es pertinente preguntar, e intentar responder, si ésta transmisión-adquisición de cultura ha interpelado la constitución de nuevos hábitos culturales, generando a su vez identidades juveniles inmersas en procesos de postproducción diferentes según el contexto regional y escolar específico en que se encontraban.

Como ya se mencionó, la investigación era uno de los objetivos centrales del modelo educativo de la UVI, así los estudiantes se enfrentaban a realizar trabajo de "campo", recién llegados a la universidad. Por iniciativa de la propia institución, para estas salidas a sus comunidades, los estudiantes acostumbraban llevar 
cámaras fotográficas o de vídeo así como grabadoras para realizar entrevistas y obtener información. Los estudiantes de la UVI grababan con el fin de "llevar el desarrollo a sus comunidades a través de realizar investigación-acción" y "no de llevarse la información como los antropólogos a los que no vuelven a ver en las comunidades". Sin embargo, al margen de las intenciones para realizar estas investigaciones, lo que importa aquí es el/los hábito(s) cultural(es) generado(s) a partir del uso de grabadoras y cámaras. Cabe destacar que grabadoras y cámaras se volvían objeto codiciado por estudiantes y docentes, al punto de adquirirlas en cuanto lograban reunir el dinero suficiente. Los estudiantes obtenían con estos aparatos la oportunidad de tener un registro gráfico y sonoro de sus tareas escolares, además de material e información para disfrute y uso extraescolar; lo que les permitía subir sus fotos y videos a sitios de Internet y, con ello, participar en espacios donde intercambiar fotos como hi5, facebook u otro tipo de redes sociales digitales."

Un caso parecido es el de la captura en word de las tareas escolares, especialmente los trabajos de final de semestre, que eran generalmente solicitados por los docentes "en computadora", situación que generaba la "necesidad" entre los estudiantes de tener computadora, USB o al menos un CD regrabable. La institución contaba con una sala de cómputo donde había 16 computadoras, que se instalaron a partir de principios de 2007 y que, para agosto del mismo año, fueron en su totalidad conectadas a Internet, momento en que aumentó cuantitativamente la presencia de estudiantes en la sala, lo que implicó la creación de diversas reglas para el empleo de las mismas. Entre otras: explicitar el tipo de páginas electrónicas a las que se podían conectar "para realizar tareas", el rechazo a descargar programas, la prohibición del chateo y la negativa a escuchar música sin audífonos, así como el anuncio de que "lo que se guarde en la computadora es responsabilidad del usuario pues se borran todos los contenidos una vez a la semana".
De esta manera a los estudiantes se les requería que las tareas fueran entregadas "por computadora", lo que implicaba su captura. Teniendo en cuenta que para la gran mayoría de los estudiantes era la primera vez que se acercaban a una computadora sin supervisión por parte de algún maestro como los del telebachillerato, la actividad de captura y elaboración de tareas resultaba lenta y tortuosa, por la falta de hábito en la escritura y el uso de la computadora. El hecho de que el contacto con las computadoras haya sido escaso para muchos estudiantes provocaba, según su explicación, que algunos de ellos prefirieran copiar (apropiarse) de los contenidos de páginas de Internet sin citarlas, para aumentar el volumen de los trabajos. Además, por la misma lentitud de captura, almacenar la información se volvía prioritario, pues un día se escribía o transcribía una parte, otro día otra, y así hasta terminar, o bien, se podía reciclar lo escrito para algún trabajo elaborado y entregado en otra materia o por otro compañero. Asimismo, los tutores aprovechaban el hecho de poder revisar en digital los documentos y devolverlos con comentarios, pues muchos de los estudiantes por falta de recursos económicos no podían estar imprimiendo cada vez que se requirieran correcciones u observaciones a sus escritos.

Sin embargo, aunque tenían recursos económicos escasos, los estudiantes buscaban formas de agenciarse los dispositivos antes señalados, cámaras, grabadoras, vídeos, computadoras, dispositivos USB. Las estrategias observadas por mí fueron tres: a) el ahorro de las becas PRONABES otorgadas por el Estado como apoyo al estudio, ${ }^{12}$ b) tener un pariente emigrante con una mejor posición económica que le permitiera regalar una computadora al estudiante, o bien, c) trabajar en periodos de descanso, por ejemplo, algunos de los jóvenes migraban en vacaciones a trabajar en la ciudad (D. F., Monterrey, etcétera), para tener dinero y con éste "comprarme mi lap" o "cambiar de cel". En particular, la atracción que generaba en ellos poseer una computadora portátil por encima de una de 
escritorio, según sus argumentos, tenía que ver con la movilidad que ofrece ésta, al poder llevar la máquina de la casa a la escuela donde se les configurara el acceso a Internet y a otras redes. Además, se debe hacer notar que, en su gran mayoría, el personal docente que laboraba en la institución, contaba con computadoras portátiles para los trabajos finales que prestaban a algunos estudiantes, pues las maquinas de la sala de cómputo resultaban insuficientes, con lo cual, los docentes apuntalaban la idea de "la necesidad que tiene el profesionista de contar con una computadora portátil para realizar su trabajo".

Pero no todo lo que tiene que ver con los hábitos culturales favorecidos por la escuela era generado a partir de la apropiación tecnológica como producto explícito del trabajo institucional. Aún sin la escuela, los actores de la Huasteca se apropiaban y reapropiaban de la tecnología actual. Un hábito cultural que identifiqué y me interesa referir aquí brevemente es el que tiene que ver con el consumo de música. La Huasteca, para distintos antropólogos y etnomusicólogos, ha sido considerada un lugar rico en expresiones culturales particulares: la música de trío interpretando huapangos, sones o distinta música ritual como el xochipitzahua, la música de xantollo, carnaval, etcétera. También existe la música de banda que, según los "lugareños" y antropólogos, provoca que se esté "perdiendo la tradicional", debido a que se quiere parecer cada vez más a la música de "moda" ya que el género de la banda se ha actualizado para seguir vigente, no a base de pasos dobles, sino a base de interpretaciones de las bandas denominadas norteña y duranguense.

Al igual que cualquier habitante de la región los estudiantes de la UVI lograban obtener un CD o un DVD pirata en las plazas ${ }^{13}$ cuyo contenido posteriormente podían "quemar", copiar o almacenar en otros dispositivos. Además podían acceder a la música "de moda", producto de las industrias culturales, a la que daban el mismo trato. Así, los sujetos observados para esta investigación, tenían acceso a la música "de moda" a través de distintos programas de la televisión abierta o en algunos casos de pago, como algunas telenovelas, series, etcétera, y a través de la programación de estaciones de radio como "La poderosa" y "La comadre". Entre los géneros preferidos, generalmente se señalaban la chunchaca, la cumbia mexicana, el duranguense, el reggaeton, las rancheras, el pop... músicas que también descargaban gratis de Internet.

Aunque en gran parte de la Huasteca no hubiera señal para realizar llamadas, puesto que algunos de los entonces universitarios habían salido de sus comunidades y tenían posibilidades de comprarse celulares, accedían a éstos para realizar la descarga o el almacenaje de música y videos. A pesar de que como ya se mencionó los celulares a veces sólo se usaban como alarma en Ixhuatlán, algunos estudiantes accedían a teléfonos celulares costosos y por lo mismo, útiles también para descargar y reproducir música e imágenes, así como para tomar fotos, grabar vídeos o audios. Generalmente, los jóvenes a partir de la escuela, aunque también sin ella, se reapropiaban de la música e imágenes en distintos contextos, incluidos los propios. Sin embargo, no perdamos de vista que interesa principalmente observar los procesos de hibridación y de postproducción de los jóvenes que transitaban por una institución educativa que privilegiaba la transmisión de contenidos escolares con enfoque intercultural, dado que se buscó identificar si había alguna especificidad de generación de hábitos culturales resultado de su paso por esa institución que los profesionalizaba, según su enfoque, a partir de la revaloración de sus culturas de origen.

\section{VI.}

Ahora bien, los nuevos hábitos culturales que identifiqué en los estudiantes de la UVI-Huasteca generados a partir de procesos de hibridación y de postproducción, significan su incorporación al empleo de las TIC y del consumo de las industrias culturales. Aquí cabe señalar 
de qué se apropian, qué re-apropian y qué postproducen. Para empezar, el hecho de que los dispositivos sean usados en contextos y prácticas ajenas a los ideados por sus creadores y difusores, me parece que sugiere la posibilidad de pensar en re-apropiaciones, no urbanas, aunque tampoco necesariamente de resistencia cultural, a partir de la resignificación y revaloración de su matriz cultural.

A partir de lo dicho, expondré a continuación situaciones que ilustran la conclusión anterior. Los estudiantes iban a traer leña acompañados por la música almacenada en su celular, desde el que no podían llamar, ni acceder a internet. La música escuchada era de diferente tipo, género y ambiente, pero principalmente la que señalamos antes como "de moda" aunque, en algunos casos, mediante una recreación propia de la misma. Otro ejemplo es que, al tener que realizar el guión de un video para un curso, el primero que elaboraron se parecía al de una telenovela, donde la protagonista era de origen humilde y se enamoraba de un rico que le correspondía. Por sugerencia e indicación del docente, la idea del video se cambió por la realización de un altar de muertos. Para esta filmación buscaron a los abuelos de una estudiante y éstos, a su vez, actuaron para dar vida a un cuento de la tradición oral local que también se filmó. Por lo anterior, se puede afirmar que, más allá de que se percibieran contribuyendo "a promover un proceso de revaloración y revitalización de las culturas propias", estos estudiantes de una universidad intercultural se encontraban interesados en la portabilidad de la música de cualquier género y en la imitación de los modelos de narrativa e historia de las telenovelas.

Sin embargo, entre la música que prefieren estos jóvenes universitarios, resalta la proveniente de una amplia diversidad de lugares y regiones como Durango, Tijuana, Panamá, la comunidad vecina, la del grupo de amigos, etcétera, sin priorizar su consumo por el de la música "de moda"; frente a lo que hacen muchos de sus hermanos inscritos en los bachilleratos del lugar. Esta capacidad de portabilidad de música diversa lleva a los estudiantes a interactuar con otros patrimonios culturales y con los productos de las industrias culturales. Por ejemplo, seleccionando y reproduciendo, junto a una canción de cualquier cantante de moda, la grabación del cante ${ }^{14}$ que llevaron a alguien la semana pasada, donde se interpretan canciones de distinto género y estilo de una manera particular, pues se recicla la música para poder interpretarla en variadas situaciones. Sin aproximarse a un uso y a una realización musical específica o distinta a la de otros jóvenes de cualquier otro contexto estos hábitos constituían una novedad para sus padres y la mayoría de los adultos de las comunidades indígenas. Asimismo, por sugerencia de los docentes, tal y como se señaló antes, accedían a realizar producciones a partir de los patrimonios culturales locales.

A lo anterior se puede agregar el uso dado a las cámaras fotográficas y las imágenes capturadas con ellas. Por ejemplo, cuando se realizó el concurso de belleza de la segunda generación en la universidad, las aspirantes se promocionaron a partir de sus propias fotografías y las vendían como suele hacerse en los bachilleratos de la zona. En estas fotografías ellas y sus fotógrafos demostraban una apropiación de símbolos producto de su consumo de la cultura de masas, pues buscaban como locaciones espacios distintos a los habituales, por ejemplo, jardines y castillos, paisajes que remiten a cuentos de hadas recreados por Disneylandia. Es de resaltar el hecho de que participar en un concurso de belleza no les llevara a cuestionarse la asignación de un rol específico a la mujer como objeto de consumo a partir de características como la belleza.

Así se puede afirmar que al menos en su etapa de formación universitaria la generación de los hábitos culturales descritos, como el uso de celulares, permite apreciar que los procesos de postproducción, aun cuando sean parecidos a los de otros sujetos, se vislumbraban como particulares al estar mediados por sus experiencias como estudiantes universitarios en una institución con enfoque intercultural y al recibir 
de ésta una orientación "extra" hacia los patrimonios culturales locales. Dado lo anterior, parece necesario señalar que los procesos de postproducción, como objeto de investigación, se asemejan al estudio de la identidad y los procesos de identificación, puesto que entender la construcción de identidades implica reconocer que éstas se componen a partir de múltiples polos de identificación e interpelación y, además, los sujetos nunca llegarán a ser las representaciones con las que se identifican o que los interpelan. Es decir, los sujetos, al configurar su identidad, siempre están posproduciendo, reciclando, reconvirtiendo, sin llegar a ser el producto previo. Así, las identidades juveniles y estudiantiles se ven (re)significadas a partir de reapropiaciones locales, aunque con referentes, como en los casos señalados tomados y no re-tomados, de las industrias culturales, pero sobre todo, a través de una mediación escolar específica que potencia la revalorización de lo "propio".

Cabe aclarar que muchos de los estudiantes de la UVI-Huasteca reconocían estar poco interesados en "las costumbres y tradiciones de los abuelitos". Sin embargo, a partir de los contenidos escolares, entraban en contacto con ideas como el aprendizaje de las lenguas de sus abuelos pues a veces ya ni sus padres hablaban las lenguas indígenas locales, la recopilación de la tradición oral como una manera de conocer la cosmovisión local o el rescate de la siembra de la milpa y la medicina tradicionales. A todo lo anterior reaccionaban, con referentes fragmentados, en parte producto de su desinterés y de su inserción en los hábitos culturales experimentados por sus migraciones, por su inserción a la vida escolar o por el consumo de productos televisivos, aunque fueran nuevos en este consumo, pues cuando eran niños apenas se había instalado el cableado eléctrico en sus localidades. Los universitarios acceden e incorporan estos discursos y hábitos culturales junto con el uso de los nuevos dispositivos electrónicos y de los productos de las industrias culturales, generando nuevos productos, aunque poco diferenciables de los del resto de los jóvenes universitarios. Por ejemplo, difunden en Internet lo registrado en grabadoras o las fotografías y videos tomados, etcétera., para sus tareas escolares. Esta apropiación y difusión los aleja de ser espectadores pasivos de las vitrinas del escaparate mundial, televisión, Internet, etcétera, aunque no nos deba hacer olvidar las condiciones de exclusión, marginación e inequidad en que se aproximan estos jóvenes estudiantes a hábitos culturales juveniles transculturalizados. Tal inequidad y experiencia de discriminación es la que, en muchos casos, ocasiona que retomen referentes de apropiación y re-apropiación desde las industrias culturales hegemónicas y no desde los contextos culturales y étnicos locales.

Para finalizar, y como parte de una reflexión sobre las condiciones de desigualdad en que se está construyendo esta globalización y globalidad de nuevos hábitos culturales, es importante mencionar que, mientras en Europa y Estados Unidos, los países y sus clases dirigentes tratan de imponer leyes para regular el mundo de las redes e individuos que comparten información a través de Internet, ${ }^{15}$ al menos en esta parte de la Huasteca, muchos sujetos tuvieron su primer acercamiento a Internet apenas en el año 2007. Para ellos, descargar o compartir información era un hábito cultural nuevo. Así, para la gran mayoría de los estudiantes de la UVI-Huasteca, la incorporación a la educación superior fue la que posibilitó su acceso a las TIC y a partir del enfoque intercultural de la universidad en que estudiaban, pudieron iniciar una reflexión sobre las imágenes a capturar, "subir" o descargar de Internet. Debido al tipo de servicio de Internet - el satelital rural- los universitarios, al momento de realizar esta investigación no podían descargar o compartir archivos "pesados", con lo que el acceso seguía resultando inequitativo y se mantenían alejados de las posibilidades de intercambio de información, libros y discos como podían realizar otros estudiantes universitarios en las ciudades. Por último, 
se debe señalar que, hoy día, las condiciones de uso de las TIC y la acumulación de sus experiencias como egresados han favorecido procesos de postproducción en los hábitos señalados que no se vislumbraron en el 2006 ni en el 2007 y que serían motivo de otras reflexiones y análisis.

\section{Notas}

I Para la elaboración de este artículo parto de información que obtuve al realizar un trabajo de campo de 16 meses y que concluyó en enero de 2008, el cual se llevó a cabo con la finalidad de realizar la tesis de grado de Doctor, en el programa de "Antropología y Bienestar Social" de la Universidad de Granada, España.

${ }^{2}$ Lo anterior implica que los derechos de autor no sean siempre respetados, pues se descarga sin pagar y sin reconocer al creador porque algunas producciones son subidas y compartidas sin su consentimiento. Sin embargo, hasta ahora, este consumo en la red da la posibilidad de posproducir e hibridar más materiales o productos y ponerlos nuevamente en circulación.

${ }^{3}$ Cfr. Para más información al respecto, se pueden consultar los trabajos Ariel de Vidas (2003 y 2009) y el coordinado por Pérez Castro (2007) entre otros.

${ }^{4}$ Desconectada, desinformada y discriminada, como me comentó un informante "cuando un indio venía a acusar que le habían robado tierra o algo, le decían que no diera lata, que se aguantara, es más que si iba a denunciar allá lo iban a encarcelar a él por andar vestido como andaban y por no hablar español". La misma fuente dijo que por miedo no denunciaban, pero que ahora la gente está más viva. Se le preguntó que por qué y respondió "pues ya salen más".

${ }^{5}$ Actualmente es Departamento y no programa.

${ }^{6}$ Expresiones recogidas al realizar el trabajo de campo.

${ }^{7}$ Lo entrecomillado se refiere a eventos que se planificaron y realizaron durante el tiempo en que se realizó el trabajo de campo. Para la realización de éstos, participaban tanto el personal de la institución (docente y administrativo) como los estudiantes.

${ }^{8}$ Cantidad total de estudiantes de las dos primeras generaciones. Con ambas se hicieron entrevistas, no así con la tercera generación que se matriculó en septiembre del 2007.

${ }^{9}$ En general se puede decir que todos los estudiantes tenían recursos económicos limitados, situación que imprimía características particulares a su apropiación del espacio universitario.

${ }^{10}$ Aunque en varios casos los padres no "ayudaban" de manera económica a sus hijos para sus estudios, pues no tenían recursos para ello, éstos mencionaron estar contentos de que sus hijos fueran estudiantes; también expresaron que podían darles motivación y consejos.

${ }^{11}$ Las cuales en el año 2006 y en el 2007 estaban comenzando su expansión. Lo que aquí llama la atención es que estos estudiantes hayan pasado de no haber usado nunca una computadora a hacer uso, principalmente, de hi5 en cuanto este apareció.

${ }^{12}$ Estas becas tienen un límite de años, dependen del promedio y difícilmente son entregadas en tiempo y forma al becario, lo cual implica que vivían de préstamos que esperaban cubrir al llegar "la beca".

${ }^{13}$ Forma en que se llama en varias zonas de México al mercado o tianguis que se pone en ciertas calles y ciudades un día a la semana para vender artículos de primera necesidad como verduras, frutas, carnes, etc., y otros artículos diversos como peines, cortaúñas, cables, cd's, dvd's, etcétera.

${ }^{14} \mathrm{Al}$ menos en Ixhuatlán ir de cante implica llevar serenata a alguien por motivo de su cumpleaños. En esas ocasiones se organiza un grupo en torno a alguien que toque la guitarra y en la noche se va a casa del festejado. Se empieza el cante cantando las mañanitas y de ahí en adelante la música que se interpreta es de lo más variada.

${ }^{15}$ Ya que según las empresas estas prácticas "merman los recursos de las industrias culturales" y vuelven necesario el establecimiento del copyright. 


\section{Bibliografía}

Arditi, Benjamín (2002), "La identidad, ese objeto esquivo", en La compañía de los libros, México: Gandhi, año l, núm. l, pp. 20-2l.

Ariel de Vidas, Anath (2003), El trueno ya no vive aquí. Representación de la marginalidad teenek (Huasteca veracruzana, México), México: Eds. CIESAS, COLSAN, CEMCA, IRD.

Ariel de Vidas, Anath (2009), Huastecos a pesar de todo. Breve historia del origen de las comunidades teenek (huastecas) de Tantoyuca, norte de Veracruz. México: Eds. CEMCA y Programa de Desarrollo Cultural de la Huasteca.

Bourriaud, Nicolas, (2004), Postproducción, Buenos Aires: Ed. Adriana Hidalgo.

Galeano, Eduardo (2004), Patas arriba. La escuela del mundo al revés, México: Siglo XXI.

García Canclini, Néstor (2003), "Las culturas híbridas en tiempos de globalización", en Culturas híbridas. Estrategias para entrar y salir de la modernidad, México: Grijalbo.
García Canclini, Néstor (2007), Lectores, espectadores e internautas, Barcelona: Gedisa.

García Castaño, Javier y Pulido, Rafael(1994), Antropología de la Educación, Salamanca: Ed. Eudema S. A.

Morales Silva, Claudia (2008), Las experiencias y los sentidos de la educación superior en dos ciclos de vida: estudio comparativo entre dos generaciones en la Huasteca veracruzana y la institución universitaria, ponencia presentada en el Foro de Estudios Interculturales en Xalapa, Veracruz, el 15 de julio de 2008.

Pérez Castro, Ana Bella (coordinadora) (2007), Equilibrio, intercambio y reciprocidad: Principios de vida y sentidos de muerte en La Huasteca, Veracruz: Consejo Veracruzano de Arte popular.

Pérez Ruiz, Maya Lorena (2008), "Presentación. Jóvenes indígenas en América Latina: ¿Globalizarse o morir?", en Pérez Ruiz, Maya Lorena (coordinadora) Jóvenes indígenas y globalización en América Latina, México: INAH, pp. 9-41.

Williams García, Roberto (2004), Los Tepehuas, México: Universidad Veracruzana. 